\title{
PEMANFAATAN ABU SERABUT KELAPA (ASK) SEBAGAI PENGGANTI SEBAGIAN SEMEN DENGAN BAHAN TAMBAH SIKAMENT-LN UNTUK MENINGKATKAN KUAT TEKAN BETON
}

\author{
Bing Santosa \\ Jurusan Teknik Sipil Fakultas Teknik Universitas Janabadra \\ Jl. Tentara Rakyat Mataram No. 55 - 57 Tel. (0274) 543676 - Fax (0274) 561039 Yogyakarta 55231 \\ e-mail: bing_santosa@yahoo.com
}

\begin{abstract}
Stength of concrete is fundamentally a function of the volume of voids in it. If the porosity of concrete is getting lower, the strength is increase, but workability more difficult. Concrete has a very high strength, if it has a very low porosity. To make concrete with small or little porosity and workable use pozzoland and superplasticizer. In this research about concrete which pozzoland from coconut fiber powder that pass sieve no. 200 as cement substitution and Sikament-LN as superplasticizer. Percentage of pozzoland as cement substitution are $0 \%, 2,5 \%, 5 \%, 7,5 \%, 10 \%, 12,5 \%, 15 \%$, and Sikament-LN is $1 \%$ from cement weight with $10 \%$ water reducer. The age of speciments test are 28 days.

The result of this research show that the maximum concrete strength with coconut fiber powder as cement substitution and Sikament-LN 1\% with $10 \%$ water reducer is 38,128 $\mathrm{MPa}$ or increase 5,663 $\mathrm{MPa}(17,443 \%)$ which is achieved by concrete with coconut fiber powder $2,5 \%$ as cement substitution compared with normal concrete.
\end{abstract}

Keywords: Coconut fiber powder, Sikament-LN, Compression strength

\begin{abstract}
ABSTRAK
Kuat tekan beton pada dasarnya adalah sebuah fungsi dari volume pori/rongga pada beton itu sendiri. Jika porositas beton semakin kecil, kekuatannya meningkat, tetapi pengerjaannya akan semakin sulit. Beton mempunyai kuat tekan tinggi, jika porositasnya sangat kecil. Untuk membuat beton dengan porositas kecil dan mudah dalam pengerjaannya digunakan pozzoland dan superplasticizer.

Penelitian ini adalah tentang beton dengan pozzoland dari Abu Serabut Kelapa (ASK) yang lolos saringan no. 200 sebagai pengganti sebagian semen dan Sikament-LN sebagai superplasticizer. Persentase Abu Serabut Kelapa (ASK) sebagai pengganti sebagian semen sebesar 0\%, 2,5\%, 5\%, 7,5\%, 10\%, 12,5\%, dan 15\%, sedangkan Sikament-LN sebesar $1 \%$ dari berat semen dengan pengurangan air sebesar 10\%. Pengujian dilaksanakan pada umur 28 hari.

Hasil penelitian menunjukkan bahwa kuat tekan beton maksimum dengan Abu Serabut Kelapa (ASK) sebagai pengganti sebagian semen dan Sikament-LN 1\% dengan pengurangan air 10\%, yaitu sebesar $38,128 \mathrm{MPa}$ atau meningkat sebesar 5,663 MPa (17,443 \%) yang dicapai pada pemakaian Abu Serabut Kelapa (ASK) sebesar 2,5\% sebagai pengganti sebagian semen dibandingkan dengan beton normal.
\end{abstract}

Kata kunci: Abu Serabut Kelapa (ASK), Sikament-LN, kuat tekan 


\section{PENDAHULUAN}

Beton merupakan bahan struktur yang paling banyak digunakan dalam pembangunan khususnya bangunan gedung, dikarenakan beton termasuk bahan yang mempunyai kuat tekan tinggi, tahan terhadap kebakaran dan keausan, tahan cuaca, dan harganya relatif murah, karena menggunakan bahan-bahan dasar dari lokal, dapat diangkut maupun dicetak sesuai keinginan, biaya perawatan relatif murah, serta dapat direncanakan kualitas mutu betonnya sesuai dengan kebutuhan.

Dengan adanya krisis moneter, maka harga bahan-bahan penyusun beton mengalami kenaikan yang cukup tinggi, baik harga semen, agregat halus, maupun kasar. Kajian dari naiknya harga bahan-bahan tersebut, maka dituntut untuk mencari dan mempergunakan pengganti bahan penyusun beton yang lebih ekonomis dan efisien tanpa mengabaikan ketentuan-ketentuan yang disyaratkan. Salah satu alternatif untuk mengatasi masalah ini, yaitu dengan menggunakan Abu Serabut Kelapa (ASK) dari daerah Purworejo, Jawa Tengah sebagai pengganti sebagian semen.

Kuat tekan beton akan semakin tinggi bila porositasnya rendah. Porositas ditentukan oleh faktor air semen. Semakin rendah nilai faktor air semen, semakin kecil porositasnya, tetapi pengerjaan atau konsistensi dari beton sangat kecil. Untuk mengatasi kesulitan pengerjaan beton tersebut digunakan chemical admixtures, yaitu superplasticizer. Salah satu superplasticizer yang dapat digunakan adalah Sikament-LN yaitu jenis bahan tambah kimia untuk pengurang kadar air (water reducer) dan pemercepat waktu ikat (accelerator) yang diproduksi oleh PT. Sika Nusa Pratama Indonesia.

Tujuan dari penelitian ini adalah untuk membuat beton alternatif dengan memanfaatkan Abu Serabut Kelapa (ASK) dan Sikament-LN sebagai bahan tambah kimia untuk mendapatkan nilai optimum dari penambahan tersebut ditinjau terhadap kuat tekan beton pada umur beton 28 hari.

Manfaat dari penelitian ini diharapkan dapat memberikan masukkan dan informasi tentang persentase penambahan Abu Serabut Kelapa (ASK) dan Sikament-LN sebagai bahan tambah kimia terhadap kuat tekan beton dan memanfaatkan limbah Abu Serabut Kelapa (ASK) semaksimal mungkin.

Pemanfaatan Abu Serabut Kelapa (ASK) Sebagai Pengganti Sebagian Semen Bahan Tambah Sikament-LN Untuk 


\section{TINJAUAN PUSTAKA}

Beton adalah campuran antara agregat halus (pasir), agregat kasar (batu pecah), air dalam jumlah tertentu, dan semen Portland atau semen hidraulik dengan atau tanpa bahan tambah. Campuran tersebut bila dituang dalam cetakan dan didiamkan, maka akan menjadi keras. Kekuatan, keawetan, dan sifat beton tergantung pada sifat-sifat dasar penyusunnya, selama penuangan adukan beton, cara pemadatan, dan rawatan selama proses pengerasan. ( Kardiyono,1992).

Bahan campuran tambahan (admixtures) adalah bahan yang bukan air, agregat, maupun semen yang ditambahkan ke dalam campuran sesaat atau selama pencampuran. Fungsi dari bahan ini adalah untuk mengubah sifat-sifat beton agar menjadi cocok untuk pekerjaan tertentu, ekonomi, atau untuk tujuan lain seperti menghemat energi. (Nawy, 1990).

Nilai kekuatan dan daya tahan (durability) beton merupakan fungsi dari banyak faktor, diantaranya adalah nilai banding campuran dan mutu bahan susun, metode pelaksanaan pengecoran, temperatur, dan kondisi pengerasannya. (Istimawan,1994).

Agregat, semen, dan air dicampur sampai bersifat plastis, sehingga mudah untuk dikerjakan. Sifat inilah yang memungkinkan adukan beton dapat dicetak sesuai dengan bentuk yang diinginkan. Dengan bercampurnya semen dengan air dan agregat, terjadi reaksi kimia yang pada umumnya bersifat hidrasi yang menghasilkan suatu pengerasan dan pertambahan kekuatan yang berlangsung terus-menerus pada suatu kelembaban dan suhu yang sesuai. Sifat beton dipengaruhi oleh perbedaan pada kekuatan dan sifat-sifat bahan, cara menakar, mencampur, juga cara-cara pelaksanaan pekerjaan. (Murdock dan Brook,1986).

Alexander (2003) melakukan pengujian mengenai Abu Serabut Kelapa (ASK) dan diperoleh hasil komposisi senyawa ASK (dalam satuan persen berat) yang terdiri atas unsur $\mathrm{SiO}_{2}$ sebanyak 42,98\%; Al 2,26\%; Fe 1,16\%. Hasil penelitian Silica Oksida yang terdapat pada ASK dapat bersifat reaktif (amorphous) yang memungkinkan $\mathrm{SiO}_{2}$ bereaksi secara kimia dengan $\mathrm{Ca}(\mathrm{OH})_{2}$ atau kapur bebas hasil dari reaksi hidrasi semen dengan air.

\section{LANDASAN TEORI}

\subsection{Materi Penyusun Beton}

\subsubsection{Semen portland}

Semen Portland adalah semen hidrolis yang dihasilkan dengan cara menghaluskan klinker yang terdiri dari silikat-silikat kalsium yang bersifat hidrolis, dan gips sebagai 
pengontrol waktu pengikatan. Komposisi semen Portland dapat dilihat pada tabel di bawah ini.

Tabel 1. Komposisi semen portland

\begin{tabular}{|l|c|c|c|}
\hline \multicolumn{1}{|c|}{ Kandungan } & Rumus & Singkatan & \% berat \\
\hline Tricalcium silicate & $3 \mathrm{CaO} \cdot \mathrm{SiO}_{2}$ & $\mathrm{C}_{3} \mathrm{~S}$ & 55 \\
\hline Dicalcium silicate & $2 \mathrm{CaO} \cdot \mathrm{SiO}_{2}$ & $\mathrm{C}_{2} \mathrm{~S}$ & 20 \\
\hline Tricalcium aluminate & $3 \mathrm{CaO} \cdot \mathrm{Al}_{2} \mathrm{O}_{3}$ & $\mathrm{C}_{3} \mathrm{~A}$ & 10 \\
\hline Tetracalcium alumino ferrite & $4 \mathrm{CaO} \cdot \mathrm{Al}_{2} \mathrm{O}_{3} \cdot \mathrm{Fe}_{2} \mathrm{O}_{3}$ & $\mathrm{C}_{3} \mathrm{AF}$ & 8 \\
\hline Gypsum & $\mathrm{CaOSO}_{3} \cdot 2 \mathrm{H}_{2} \mathrm{O}$ & $\stackrel{\mathrm{CS} \mathrm{H}_{2}}{ }$ & 5 \\
\hline
\end{tabular}

Dari Tabel 1 dapat dilihat bahwa $\mathrm{C}_{2} \mathrm{~S}$ dan $\mathrm{C}_{3} \mathrm{~S}$ adalah dua senyawa yang paling penting dan memberikan konstribusi yang paling besar terhadap kekuatan pasta semen. Oksida ini akan membentuk massa yang padat setelah bereaksi dengan air. Kedua senyawa ini terkandung dalam semen Portland lebih dari tiga perempat bagian. Sedangkan $\mathrm{C}_{3} \mathrm{~A}$ memberi konstribusi yang kecil bagi kekuatan semen kecuali pada usia awal dan ketika proses pengerasan semen pada kondisi lingkungan yang mengandung sulfat. Senyawa ini bereaksi secara eksotermik dan berpengaruh pada panas hidrasi tertinggi. Secara singkat dapat dijelaskan reaksi hidrasi yang terjadi adalah sebagai berikut (Shetty, 2000) :

$$
\begin{aligned}
& 2\left(3 \mathrm{CaO} . \mathrm{SiO}_{2}\right)+6 \mathrm{H}_{2} \mathrm{O} \rightarrow 3 \mathrm{CaO} .2 \mathrm{SiO}_{2} .3 \mathrm{H}_{2} \mathrm{O}+3 \mathrm{Ca}(\mathrm{OH})_{2} \\
& 2\left(3 \mathrm{CaO} . \mathrm{SiO}_{2}\right)+4 \mathrm{H}_{2} \mathrm{O} \rightarrow \mathrm{CaO} .2 \mathrm{SiO}_{2} .3 \mathrm{H}_{2} \mathrm{O}+\mathrm{Ca}(\mathrm{OH})_{2} \\
& \text { butir semen }+ \text { Air } \rightarrow \text { Pasta semen }+ \text { Kapur bebas } \\
& \mathrm{CaO} \cdot \mathrm{Al}_{2} \mathrm{O}_{3}+\mathrm{CaO} \mathrm{SO}_{3} .2 \mathrm{H}_{2} \mathrm{O}+10 \mathrm{H}_{2} \mathrm{O} \rightarrow 4 \mathrm{CaO} \cdot \mathrm{Al}_{2} \mathrm{O}_{3} \cdot \mathrm{SO}_{3} .3 \mathrm{H}_{2} \mathrm{O}
\end{aligned}
$$

Tricalcium aluminate + Gypsum + Air $\rightarrow$ Monosulfoaluminate

Dengan jumlah air yang sama reaksi $\mathrm{C}_{3} \mathrm{~S}$ menghasilkan kapur bebas $\left(\mathrm{Ca}(\mathrm{OH})_{2}\right)$ lebih dari dua kali lipat jumlahnya dibandingkan $\mathrm{C}_{2} \mathrm{~S}$. Kapur bebas ini akan mengurangi kekuatan semen karena besar kemungkinannya larut dalam air dan menguap, sehingga beton menjadi porous.

Pemanfaatan Abu Serabut Kelapa (ASK) Sebagai Pengganti Sebagian Semen Bahan Tambah Sikament-LN Untuk 


\subsubsection{Agregat}

Agregat ialah butiran mineral alami yang berfungsi sebagai bahan pengisi dalam campuran beton. Agregat ini kira-kira menempati sebanyak $70 \%$ volume beton. Walaupun namanya hanya sebagai bahan pengisi, akan tetapi agregat sangat berpengaruh terhadap sifat-sifat betonnya, sehingga pemilihan agregat merupakann suatu bagian penting dalam pembuatan mortar/ beton. Dalam praktek, agregat umumnya digolongkan menjadi tiga kelompok, yaitu:

1. Batu untuk besar butiran lebih dari $40 \mathrm{~mm}$.

2. Kerikil untuk besar butiran antara $5 \mathrm{~mm}$ dan $40 \mathrm{~mm}$.

3. Pasir untuk besar butiran antara $0,15 \mathrm{~mm}$ dan $5 \mathrm{~mm}$.

Agregat yang akan digunakan untuk bahan bangunan sebaiknya memenuhi persyaratan sebagai berikut :

1. Butirannya tajam, kuat, dan bersudut.

2. Tidak mengandung tanah atau kotoran yang lewat ayakan 0,075 .

3. Tidak mengandung garam yang menghisap air dan udara.

4. Tidak mengandung zat organis.

5. Mempunyai variasi besar butir (gradasi) yang baik sehingga rongganya sedikit (untuk pasir modulus halus butirnya antara 1,50-3,80).

6. Bersifat kekal, tidak hancur atau berubah karena cuaca.

7. Untuk beton dengan tingkat keawetan yang tinggi, agregat harus mempunyai tingkat reaktif yang negatif terhadap alkali.

8. Untuk agregat kasar, tidak boleh mengandung butiran-butiran yang pipih dan panjang lebih dari $20 \%$ dari berat keseluruhan.

Agregat yang banyak digunakan untuk campuran beton adalah pasir dan kerikil karena pertimbangan ekonomis dan kemudahan pengerjaan. Sifat yang paling penting dari suatu agregat (batu-batuan, kerikil dan lain-lain) ialah kekuatan hancur dan ketahanannya terhadap benturan, yang dapat mempengaruhi ikatannya dengan pasta semen, porositas dan karakteristik penyerapan air yang mempengaruhi daya tahan terhadap agresi kimia dan penyusutan.

Penggunaan bahan bangunan atau agregat pada adukan dimaksudkan untuk :

1. Penghematan penggunaan semen Portland.

2. Menghasilkan kekuatan besar pada beton.

3. Mengurangi susut pengerasan pada beton. 
4. Mencapai susunan pampat betonnya dengan gradasi (variasi ukuran butir) yang baik dari agregatnya.

5. Mengontrol kemudahan (workability) adukan beton plastis dengan gradasi baik.

Agregat yang dapat digunakan sebagai bahan pengisi beton antara lain :

1. Batu pecah, ini merupakan butir-butir hasil pemecahan batu, butirnya berbentuk tajam, sehingga sedikit memperkuat betonnya.

2. Tanah liat bakar, tanah liat dengan kadar air tertentu dibuat berbutir sekitar 5-25 mm, kemudian dibakar. Hasil pembakaran tersebut berupa bola yang keras tetapi ringan dan berpori serta serapan airnya sebanyak $8-12 \%$, beton dengan agregat ini berat jenisnya sekitar 1,9 .

3. Lempung bekah, agregat ini sangat ringan, berat jenisnya 1,15 . Beton dengan agregat ini mempunyai ketahanan tinggi terhadap panas dan mempunyai sifat meredam suara yang baik.

4. Agregat abu terbang, agregat ini adalah hasil dari pemanasan abu terbang sampai meleleh dan mengeras lagi, sehingga berbentuk butir-butir seperti kerikil.

\subsubsection{Air}

Air merupakan bahan yang penting dalam pembuatan campuran beton yang berpengaruh pada sifat mudah dikerjakan (workability), kekuatan susut, dan keawetan. Air yang digunakan dalam campuran beton harus bersih, tidak boleh mengandung minyak, asam, garam, zat organik atau bahan-bahan lain yang bersifat merusak beton dan baja tulangan. Hal ini penting dalam pemilihan air yang digunakan untuk campuran beton agar memenuhi syarat :

1. tidak mengandung lumpur atau benda melayang lainnya lebih dari 2 gram/ liter,

2. tidak mengandung garam yang dapat merusak beton atau asam dan zat organik lainnya tidak lebih dari 15 gram/liter,

3. tidak mengandung chlorida $(\mathrm{CI})$ lebih dari 0,5 gram/liter,

4. tidak mengandung sulfat lebih dari 1 gram/liter.

Air diperlukan untuk bereaksi dengan semen dan menjadi bahan pelumas antara butir-butir agregat agar mudah dikerjakan dan dipampatkan. Kualitas air sangat mempengaruhi mutu beton. Air yang bebas dari lumpur, tidak mengandung garam, Chlorida dan senyawa sulfat sangat dianjurkan untuk digunakan.

Pemanfaatan Abu Serabut Kelapa (ASK) Sebagai Pengganti Sebagian Semen Bahan Tambah Sikament-LN Untuk 


\subsection{Pozzoland}

Pozzoland dapat dipakai sebagai bahan tambahan atau pengganti sebagian semen Portland. Bila dipakai sebagai pengganti sebagian semen Portland, umumnya berkisar 10 sampai 35 persen dari berat semen. Sedangkan sebagai bahan tambah, pozzoland akan menjadikan beton lebih mudah diaduk, lebih rapat air, dan lebih tahan terhadap serangan kimia.

Beberapa pozzoland dapat mengurangi pemuaian beton yang terjadi akibat proses reaksi alkali-agregat (reaksi alkali dalam semen dengan silika dalam agregat). Dengan demikian mengurangi retak-retak beton akibat reaksi tersebut. Pada pembuatan beton massa (mass concrete), misalnya dam, pemakaian pozzoland sangat menguntungkan, karena menghemat semen dan mengurangi panas hidrasi. Panas hidrasi pada beton massa dapat mengakibatkan retakan yang serius.

Pozzoland didefinisikan sebagai material yang mengandung silika dan/atau alumina, dalam bentuk yang halus. Umumnya pozzoland memiliki kandungan silika $\left(\mathrm{SiO}_{2}\right)$ dan alumina $\left(\mathrm{Al}_{2} \mathrm{O}_{3}\right)$ yang tinggi dan unsur ini diharapkan bereaksi dengan kapur bebas $\left(\mathrm{Ca}(\mathrm{OH})_{2}\right)$. Secara singkat reaksi yang diharapkan adalah sebagai berikut :

$$
\mathrm{Ca}(\mathrm{OH})_{2}+\mathrm{SiO}_{2} \rightarrow \mathrm{C}-\mathrm{S}-\mathrm{H}
$$

\subsection{Abu Serabut Kelapa (ASK)}

Serabut kelapa ini digunakan sebagai bahan bakar memasak dalam usaha kecil pembuatan roti, bahan bakar pembuatan genteng, dan batu bata yang dilakukan secara tradisional di desa-desa. Abu serabut kelapa sebagai limbah buangan, sebenarnya memiliki unsur yang bermanfaat untuk peningkatan mutu beton.

Seiring dengan semakin meningkatnya pemakaian bahan-bahan tambah (additive) untuk beton, maka teknologi sederhana ini dapat dijadikan sebagai alternatif yang murah dan tepat guna. Pemanfaatan limbah untuk bahan konstruksi disamping akan memberikan penyelesaian permasalahan terhadap lingkungan juga akan meningkatkan mutu bahan konstruksi. Satu hal yang merupakan nilai tambah, nilai guna limbah, serta menciptakan lapangan pekerjaan dan mengurangi dampak negatif.

Pada umumnya limbah Abu Serabut Kelapa (ASK) terdiri dari unsur organik seperti serat, cellulose, dan lignin. Disamping itu limbah ini juga mengandung mineral yang terdiri dari silika, aluminia, dan oksida-oksida besi. $\mathrm{SiO}_{2}$ dalam abu serabut kelapa merupakan hal yang paling penting, karena dapat bereaksi dengan kapur $\left(\mathrm{Ca}(\mathrm{OH})_{2}\right)$ dan Air $\left(\mathrm{H}_{2} \mathrm{O}\right)$. Hasil utama dari proses di atas ialah $\mathrm{C}_{3} \mathrm{~S}_{2} \mathrm{H}_{3}$ atau C-S-H yang biasa disebut tobermorite, berbentuk 
gel (gelatine) yang dapat mengkristal.

Dari pengujian Abu Serabut Kelapa (ASK) yang telah dilakukan di BBTKL (Balai Besar Teknik Kesehatan Lingkungan), diperoleh hasil komposisi senyawa ASK (dalam satuan persen berat) yang terdiri atas unsur $\mathrm{SiO}_{2}$ sebanyak 47,55\%; $\mathrm{Al}_{2} \mathrm{O}_{3} 1,05 \% ; \mathrm{MgO}$ $2,65 \%$; dan kadar air 5,29\%.

\subsection{Bahan Kimia tambahan}

Bahan kimia tambahan (chemical admixture) ialah bahan kimia (berupa bubuk atau cairan) yang dicampurkan pada adukan beton selama pengadukan dalam jumlah tertentu untuk mengubah beberapa sifatnya. Bahan kimia tambahan dapat dibedakan menjadi 5 jenis :

1. Bahan kimia tambahan untuk mengurangi jumlah air yang dipakai. Dengan pemakaian bahan ini diperoleh adukan dengan faktor air semen lebih rendah pada nilai kekentalan adukan yang sama, atau diperoleh kekentalan adukan lebih encer pada faktor air semen sama.

2. Bahan kimia tambahan untuk memperlambat proses ikatan beton. Bahan ini digunakan misalnya pada suatu kasus dimana jarak antara tempat pengadukan beton dan tempat penuangan adukan cukup jauh, sehingga selisih waktu antara mulai pencampuran dan pemadatan lebih dari 1 jam.

3. Bahan kimia tambahan untuk mempercepat proses ikatan dan pengerasan beton. Bahan ini digunakan jika penuangan adukan dilakukan di bawah permukaan air, atau pada struktur beton yang memerlukan waktu penyelesaian segera, misalnya perbaikan landasan pacu pesawat udara, balok prategang jembatan, dan sebagainya.

4. Bahan kimia tambahan yang berfungsi ganda, yaitu untuk mengurangi air dan memperlambat proses ikatan.

5. Bahan kimia tambahan yang berfungsi ganda, yaitu untuk mengurangi air dan mempercepat proses ikatan dan pengerasan beton.

Selain 5 jenis di atas, ada 2 jenis lain yang lebih khusus, yaitu :

1. Bahan kimia tambahan yang digunakan untuk mengurangi jumlah air campuran sampai sebesar $10 \%$ atau bahkan lebih, untuk menghasilkan adukan beton dengan kekentalan sama (air dikurangi sampai $10 \%$ lebih, namun adukan beton tidak bertambah kental).

2. Bahan kimia tambahan dengan fungsi ganda, yaitu mengurangi air sampai $10 \%$ atau lebih dan memperlambat waktu pengikatan.

Pemanfaatan Abu Serabut Kelapa (ASK) Sebagai Pengganti Sebagian Semen Bahan Tambah Sikament-LN Untuk 


\subsection{Sikament-LN}

Sikament-LN adalah jenis bahan tambah kimia untuk pengurang kadar air (water reducer) dan pemercepat waktu ikat (accelerator) yang diproduksi oleh PT. Sika Nusa Pratama Indonesia. Sesuai dengan namanya (water reducer), admixture jenis ini berguna untuk mengurangi air campuran tanpa mengurangi workability. Admixture ini juga dapat mempercepat proses ikatan dan pengerasan beton yang memerlukan waktu penyelesaian segera atau sebagai accelerator.

\subsection{Faktor Air Semen}

Faktor air semen (FAS) adalah perbandingan antara berat air dan berat semen di dalam campuran beton, semakin rendah nilai faktor air semen (FAS), maka semakin tinggi kekuatan tekan betonnya.

Air yang berlebihan akan menyebabkan banyaknya gelembung air setelah hidrasi selesai, sedangkan air yang terlalu sedikit akan menyebabkan proses hidrasi tidak seluruhnya selesai hingga menyebabkan beton berkurang kekuatannya. Berikut ini adalah grafik yang menunjukan hubungan antara faktor air semen (FAS) dengan kuat tekan beton.

Duff Abrams mengusulkan menggunakan faktor air semen (FAS) dengan kuat tekan beton secara umum sebagai berikut :

$$
f^{\prime} c=\frac{A}{B^{1,5 x}}
$$

Dengan $\mathrm{f}^{\prime} \mathrm{c}=$ Kuat tekan beton pada umur tertentu $(\mathrm{MPa})$

$$
\mathrm{X}=\text { Faktor Air Semen }
$$

$\mathrm{A}, \mathrm{B}=$ Konstanta

Dari rumus di atas tampak bahwa semakin rendah nilai FAS, semakin tinggi kuat tekan betonnya. Tetapi jika FAS terlalu rendah maka adukan beton sulit dipadatkan, sehingga kuat tekan betonnya semakin rendah. 


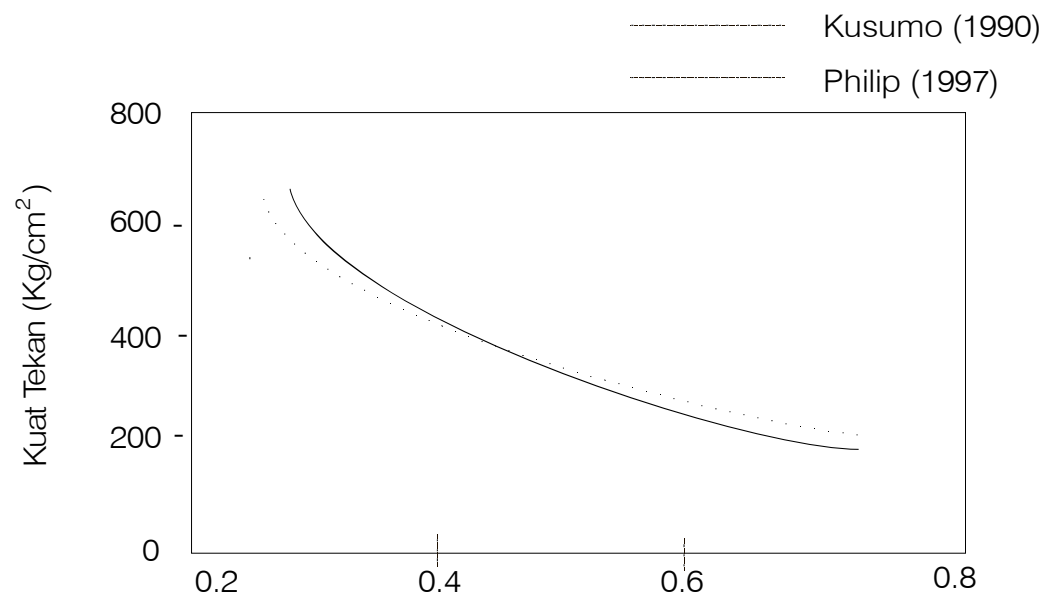

Gambar 1. Hubungan Antara FAS dengan Kuat Tekan Beton

\subsection{Metode Perencanaan Campuran Beton}

Perencanaan beton pada penelitian ini meliputi perencanaan beton normal dengan metode berdasarkan pada standar dari SK SNI T-15 - 1990 - 03 (Tata Cara Pembuatan Rencana Campuran Beton Normal).

Perencanaan adukan dimaksudkan untuk mendapatkan beton yang sebaik-baiknya dengan berdasarkan pada :

1. Kuat tekan beban

2. Mudah dikerjakan

3. Tahan lama

4. Murah dan tahan aus

\subsection{Nilai Slump}

Bila beton tidak dipadatkan secara sempurna, sejumlah gelembung udara dimungkinkan terperangkap dan mengakibatkan rongga lebih banyak lagi. Beton dengan jumlah volume minimal adalah yang terpadat dan terkuat, yaitu dengan menggunakan jumlah air yang minimal konsisten dengan derajat workability yang dibutuhkan untuk memberikan kepadatan maksimal.

Workability merupakan ukuran dari tingkat kemudahan beton segar untuk diaduk, disalurkan, dituang, dipadatkan, dan dirapikan. Unsur-unsur yang mempengaruhi sifat workability adalah :

Pemanfaatan Abu Serabut Kelapa (ASK) Sebagai Pengganti Sebagian Semen Bahan Tambah Sikament-LN Untuk 
1. jumlah air yang dipakai dalam campuran adukan beton. Semakin banyak air yang dipakai semakin mudah adukan beton dikerjakan,

2. penambahan semen ke dalam campuran juga memudahkan cara pengerjaan adukan betonnya, karena diikuti dengan bertambahnya air campuran untuk memperoleh nilai FAS tetap,

3. gradasi campuran pasir dan kerikil. Bila campuran pasir dan kerikil mengikuti gradasi yang telah disarankan maka adukan beton akan mudah dikerjakan,

4. pemakaian butir-butir batuan mempermudah cara pengerjaan beton,

5. pemakaian butir maksimum kerikil yang dipakai juga berpengaruh terhadap tingkat kemudahan dikerjakan,

6. cara pemadatan adukan beton menentukan sifat pengerjaan yang berbeda, bila pemadatannya dilakukan dengan cara menggunakan alat getar maka tingkat kelacakannya juga berbeda, sehingga diperlukan jumlah air yang lebih sedikit dibandingkan bila dipadatkan dengan tangan.

Untuk mengetahui tingkat workability (kemudahan dalam pengerjaan) beton, biasanya dilakukan pengujian slump. Pemeriksaan slump sdilakukan terhadap beton yang masih segar. Makin besar nilai slump makin encer adukan beton tersebut. Percobaan slump menggunakan alat-alat sebagai berikut.

1. Corong baja berbentuk konus berlubang pada kedua ujungnya. Bagian bawah berdiameter $20 \mathrm{~cm}$ dan bagian atas berdiameter $10 \mathrm{~cm}$ dengan tinggi $30 \mathrm{~cm}$.

2. Tongkat baja berdiameter $16 \mathrm{~mm}$, panjang $60 \mathrm{~cm}$ dengan bagian ujung dibulatkan.

Skema pelaksanaan pengujian slump terhadap adukan beton segar dapat dilihat pada Gambar 2.

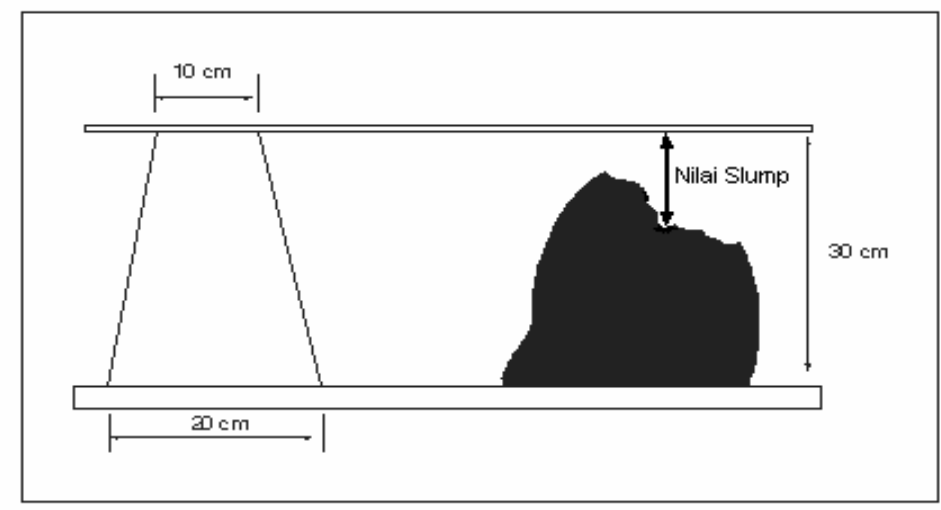

Gambar 2. Pengujian slump 
Untuk mencegah pengadukan adukan beton yang terlalu kental atau terlalu encer, dianjurkan menggunakan nilai slump yang terletak pada batas-batas yang diajukan seperti pada Tabel 2 berikut ini.

Tabel 2. Nilai slump untuk berbagai macam pekerjaan

\begin{tabular}{|l|c|c|}
\hline \multicolumn{1}{|c|}{$\begin{array}{c}\text { Pemakaian Beton } \\
\text { (berdasarkan jenis struktur yang dibuat) }\end{array}$} & \multicolumn{2}{c|}{ Slump (cm) } \\
\cline { 2 - 3 } & Maksimum & Minimum \\
\hline Dinding, plat pondasi dan pondasi telapak bertulang & 12,5 & 5,0 \\
\hline $\begin{array}{l}\text { Pondasi telapak tidak bertulang, kaison dan konstruksi } \\
\text { bawah tanah }\end{array}$ & 9,0 & 2,5 \\
\hline Plat, balok, kolom dan dinding & 15,0 & 7,5 \\
\hline Pengerasan jalan & 7,5 & 5,0 \\
\hline Pembetonan missal (Beton massa) & 7,5 & 2,5 \\
\hline
\end{tabular}

Nilai slump adalah besar penurunan permukaan adukan beton segar pada percobaan slump sesuai dengan prosedur yang ada. Percobaan slump adalah suatu cara untuk mengukur kelecakan adukan beton segar, yang dipakai pula untuk memperkirakan tingkat kemudahan dalam pengerjaannya.

Nilai slump juga dipengaruhi oleh faktor air semen (FAS). Semakin tinggi faktor air semen (FAS) maka nilai slump akan semakin tinggi yakni pemakaian banyak air sedikit semen, sehingga pasta semen encer mengakibatkan adukan mempunyai nilai slump lebih tinggi.

Karena pentingnya nilai slump yang dipakai sebagai petunjuk dari tingkat workability adukan beton, maka pada waktu pengujian slump harus dilakukan dengan hati-hati dan cermat, serta menggunakan prosedur yang ada agar diperoleh data nilai slump yang akurat dari setiap pengujian yang dilaksanakan.

\subsection{Perawatan Benda Uji}

Perawatan benda uji yang dilakukan adalah perawatan basah, yaitu dengan merendam benda uji pada kolam/bak perendaman yang berisi air tawar sampai umur beton mencapai 28 hari. Setelah umur perawatan cukup (sesuai dengan umur beton) benda uji kemudian diuji.

Pemanfaatan Abu Serabut Kelapa (ASK) Sebagai Pengganti Sebagian Semen Bahan Tambah Sikament-LN Untuk 


\subsection{Kuat Tekan Beton}

Pengujian kuat tekan beton normal dilakukan pada umur 28 hari pada masing masing benda uji. Pengujian dilakukan dengan mesin uji tekan, kemudian benda uji ditekan searah dengan tinggi silinder beton sampai benda uji tersebut pecah dan jarum petunjuk tidak naik lagi.

Kuat tekan benda uji dapat diperoleh dengan rumus :

$$
f^{\prime} C=\frac{P}{A}
$$

dengan :

$\mathrm{f}^{\prime} \mathrm{c} \quad=$ Kuat tekan beton pada umur tertentu (MPa)

$\mathrm{P} \quad=$ Beban maksimum $(\mathrm{N})$

A = Luas bidang tekan beton atau luas penampang $\left(\mathrm{mm}^{2}\right)$

Kekuatan tekan rata-rata beton (fcr) dapat diperoleh berdasarkan persamaan sebagai berikut

$$
\mathrm{fcr}=\frac{\sum_{1}^{n} f_{c}}{n}
$$

dengan :

$\mathrm{fc}=$ Kuat tekan beton.

$\mathrm{n}$ = Banyaknya benda uji.

Devisiasi standar sangat mempengaruhi mencari nilai kuat tekan rata-rata. Devisiasi standar ditentukan berdasarkan tingkat mutu pelaksanaan di lapangan. Makin baik mutu pelaksanaannya (pengujian, pengawasan, dan peralatan), makin kecil nilai devisiasi standar yang ditetapkan atau sebaliknya. Devisiasi standar dihitung dengan persamaan :

$$
\begin{gathered}
S=\sqrt{\frac{\sum_{1}^{n}\left(f c-f^{\prime} c r t\right)}{n-1}} \\
\text { Dengan : f'c } \quad=\text { Kuat tekan beton pada umur tertentu (MPa) } \\
\mathrm{f}^{\prime} \mathrm{crt}=\text { Kuat tekan rata-rata (MPa) } \\
\mathrm{n} \quad=\text { Jumlah benda uji }
\end{gathered}
$$

Kuat tekan rata-rata yang direncanakan dihitung dengan persamaan :

$\mathrm{f}^{\prime} \mathrm{crt}=\mathrm{f}^{\prime} \mathrm{c}+\mathrm{m}$

dengan : f'crt $=$ Kuat tekan beton rata-rata $(\mathrm{MPa})$

$\mathrm{f}^{\prime} \mathrm{c}=$ Kuat tekan beton pada umur tertentu (MPa)

$\mathrm{m} \quad=$ Nilai tambah $=\mathrm{K} . \mathrm{S}$ 


$$
\begin{array}{ll}
\mathrm{K} & =1,64 \\
\mathrm{~S} & =\text { Devisiasi standar }
\end{array}
$$

Sebagai gambaran bagaimana cara menilai tingkat pengendalian mutu beton, disini diberikan pedoman yang biasa dipakai di Inggris yaitu dilakukan dengan Tabel 3 sebagai berikut :

Tabel 3. Nilai devisiasi standar untuk berbagai tingkat pengendalian mutu pekerjaan

\begin{tabular}{|c|c|}
\hline Tingkat Pengendalian Mutu Pekerjaan & Devisiasi Standar (MPa) \\
\hline Memuaskan & 2,8 \\
\hline Sangat baik & 3,5 \\
\hline Baik & 4,2 \\
\hline Cukup & 5,6 \\
\hline Jelek & 7,0 \\
\hline Tanpa kendali & 8,4 \\
\hline
\end{tabular}

Tabel 4. Faktor Pengali Untuk Devisiasi Standar bila data hasil uji yang tersedia kurang dari 30

\begin{tabular}{|c|c|}
\hline Jumlah Benda Uji & Faktor Pengali Devisiasi Standar \\
\hline Kurang dari 15 & Lihat ayat 3.2.1 butir 1 sub butir 5 \\
\hline 15 & 1,16 \\
\hline 20 & 1,08 \\
\hline 25 & 1,03 \\
\hline 30 atau lebih & 1,00 \\
\hline
\end{tabular}

\section{METODE PENELITIAN}

Pelaksanaan penelitian ini diawali dengan persiapan bahan dan alat-alat, dilanjutkan dengan pengujian bahan. Setelah bahan yang telah diuji memenuhi syarat dilanjutkan dengan perhitungan campuran beton untuk memperoleh kebutuhan masing-masing bahan adukan. 
Sebelum adukan dituang ke dalam cetakan yang berbentuk silinder, terlebih dahulu diuji kekentalannya dengan slump test. Silinder beton dilepas setelah benda uji berumur 24 jam dan direndam dalam air selama 27 hari. Benda uji dites pada umur 28 hari.

\section{HASIL PENELITIAN}

\subsection{Workability}

Pengujian slump dilaksanakan pada saat beton masih dalam keadaan segar untuk mengetahui tingkat kelecakan adukan yang berpengaruh pada kemudahan pengerjaan (workability) pada saat beton dipadatkan. Nilai slump yang direncanakan untuk beton normal yaitu 60 - $180 \mathrm{~mm}$. Dari hasil penelitian diperoleh nilai rerata slump beton normal sebesar $115 \mathrm{~mm}$, yang berarti nilai slump tersebut masih berada dalam batas yang telah ditetapkan. Sedangkan nilai slump untuk beton yang menggunakan Abu Serabut Kelapa (ASK) sebagai pengganti sebagian semen dan Sikament-LN 1\%, serta pengurangan air sebesar 10\% tidak mengalami perubahan yang berarti atau masih dalam batas nilai slump pada perencanaan awal. Hasil pengujian slump dapat dilihat pada Gambar 3.

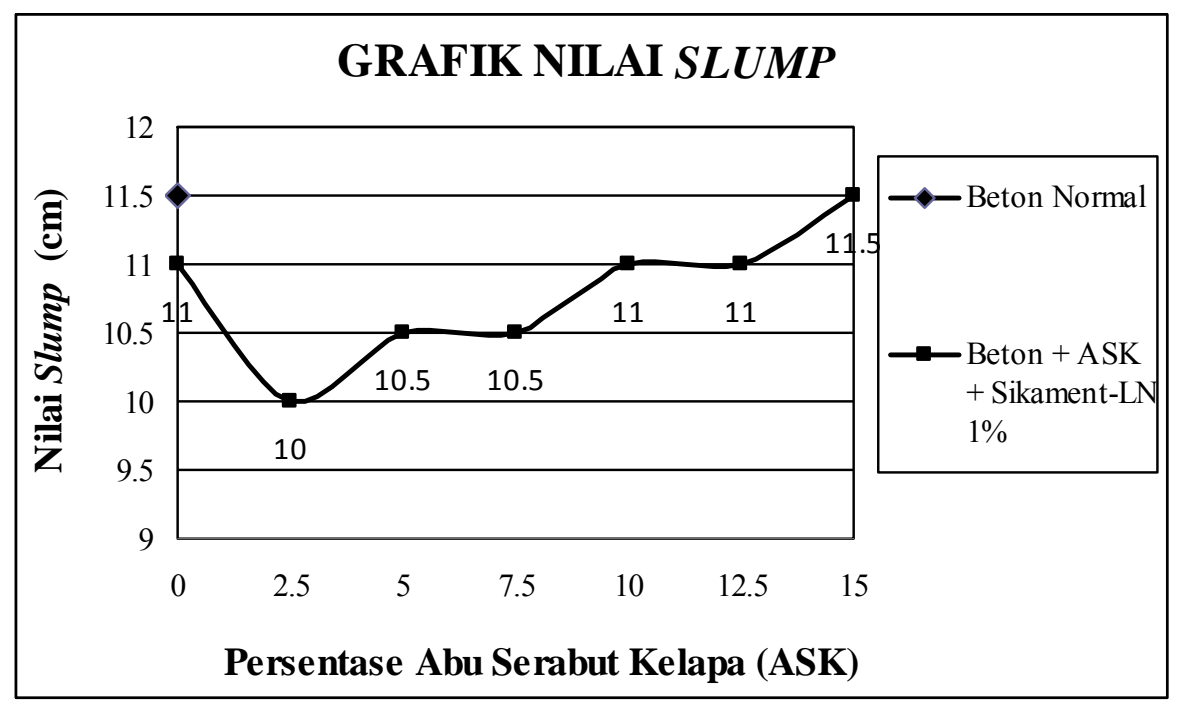

Gambar 3. Nilai slump beton normal dengan beton menggunakan Abu Serabut Kelapa (ASK) sebagai pengganti sebagian semen, Sikamen-LN 1\%, dan pengurangan air $10 \%$. 


\subsection{Kuat tekan beton}

Hasil kuat tekan rata-rata beton normal sebesar 27,18 MPa, sedangkan kuat beton normal yang ditargetkan sebesar $20 \mathrm{MPa}$. Kuat tekan beton yang menggunakan Abu Serabut Kelapa (ASK) sebagai pengganti sebagian semen dan Sikament-LN 1\%, serta pengurangan air sebesar $10 \%$ cenderung mengalami peningkatan kuat tekannya dibandingkan beton normal pada persentase pemakaian Abu Serabut Kelapa (ASK) sebesar 2,5\%, 5\%, 7,5\%, dan 10\%, sedangkan pada persentase pemakaian Abu Serabut Kelapa (ASK) sebesar 12,5\% dan 15\% sebagai pengganti sebagian semen dan Sikament-LN 1\%, serta pengurangan air sebesar $10 \%$ kuat tekannya lebih rendah dibandingkan dengan beton normal. Kuat tekan tertinggi dicapai pada persentase pemakaian Abu Serabut Kelapa (ASK) sebesar 2,5\% sebagai pengganti sebagian semen yaitu sebesar 38,128 MPa. Grafik kuat tekan dapat dilihat pada Gambar 4.

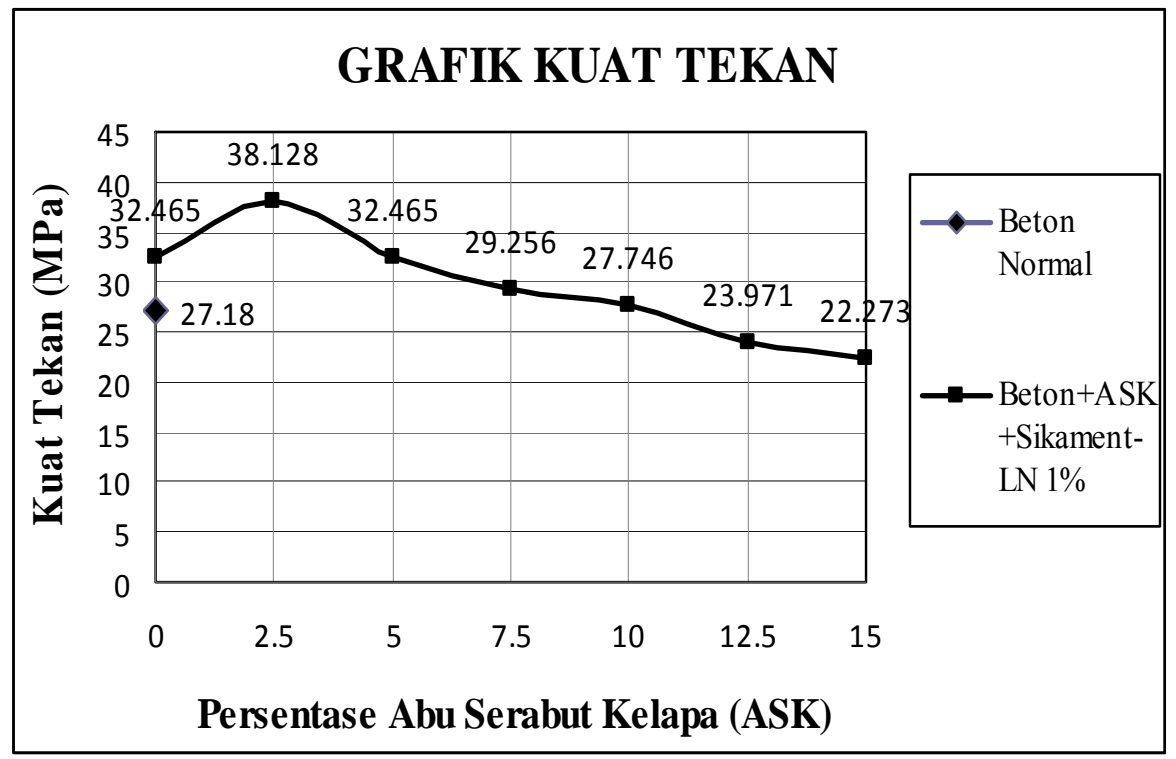

Gambar 4. Kuat tekan beton normal dengan beton menggunakan Abu Serabut Kelapa (ASK) sebagai pengganti sebagian semen, Sikamen-LN 1\%, dan pengurangan air $10 \%$. 


\section{KESIMPULAN DAN SARAN}

\subsection{Kesimpulan}

Berdasarkan hasil penelitian tentang Pemanfaatan Abu Serabut Kelapa (ASK) sebagai Pengganti Sebagian Semen dengan Bahan Tambah Sikament-LN untuk meningkatkan Kuat Tekan Beton, dapat disimpulkan sebagai berikut :

1. Nilai slump tidak mengalami perubahan yang berarti.

2. Kuat tekan beton mengalami peningkatan dibandingkan dengan beton normal sampai dengan persentase pemakaian Abu Serabut Kelapa (ASK) sebesar 2,5\%, 5\%, 7,5\%, dan $10 \%$, Sikament-LN 1\%, serta pengurangan air sebesar $10 \%$.

3. Kuat tekan beton maksimum sebesar 38,128 MPa dicapai pada pemakaian Abu Serabut Kelapa (ASK) sebagai pengganti sebagian semen sebesar 2,5\% dan Sikament-LN 1\%, serta pengurangan air sebesar $10 \%$.

4. Beton mengalami penurunan kuat tekan dibandingkan dengan beton normal pada penggunaan Abu Serabut Kelapa (ASK) sebagai pengganti sebagian semen sebesar $12,5 \%$ dan $15 \%$, serta Sikament-LN 1\% dan pengurangan air sebesar $10 \%$.

\subsection{Saran}

Untuk memperoleh pengetahuan yang lebih mendalam mengenai pemanfaatan Abu Serabut Kelapa (ASK) sebagai pengganti sebagian semen dengan bahan tambah Sikament$L N$ untuk meningkatkan kuat tekan perlu diadakan penelitian lebih lanjut, sebagai berikut:

1. Dilakukan penelitian menggunakan FAS yang berbeda.

2. Penelitian menggunakan Abu Serabut Kelapa (ASK) dengan interval 1\%.

\section{DAFTAR PUSTAKA}

1. Anonim, (1971). Peraturan Beton Bertulang Indonesia ( PBI 1971 ), Departemen Pekerjaan Umum.

2. Anonim, (1990). Tata Cara Pembuatan Rencana Campuran Beton Normal ( SK SNI T - 15 - 1990 - 03 ), DPU Yayasan LPMB, Bandung.

3. Kardiyono, T., (1992). Buku Ajar Teknologi Beton, Universitas Gajah Mada, Yogyakarta.

4. Murdock, L.J., Brook, K.M., (1986). Bahan dan Praktek Beton, Erlangga, Jakarta.

5. Nawy, E.G., (1990). Beton Bertulang, PT. Eresco, Bandung. 
6. Nevil, A.M., (1995). Properties of Concrete ( Fourth and Final Edition ), Longman Group Limited, England.

7. Nugraha, P., (1989). Teknologi Beton, Universitas Kristen Petra, Surabaya.

8. Shetty, M.S., (1992). Concrete Technology ( Theory and Practice ), Ram Nagar, New Delhi. 